\title{
Loss Modeling of Large Hydrogenerators for Cost Estimation of Reactive Power Services
}

This paper was downloaded from TechRxiv (https://www.techrxiv.org).

\section{LICENSE}

CC BY 4.0

SUBMISSION DATE / POSTED DATE

$10-12-2021 / 13-12-2021$

\section{CITATION}

Karekezi, Yannick Cyiza; Øyvang, Thomas; Nøland, Jonas Kristiansen (2021): Loss Modeling of Large Hydrogenerators for Cost Estimation of Reactive Power Services. TechRxiv. Preprint. https://doi.org/10.36227/techrxiv.16860514.v1

$\mathrm{DOI}$

10.36227/techrxiv.16860514.v1 


\title{
Loss Modeling of Large Hydrogenerators for Cost Estimation of Reactive Power Services
}

\author{
Yannick Cyiza Karekezi, Student Member, IEEE, Thomas Øyvang, Member, IEEE, \\ and Jonas Kristiansen Nøland, Member, IEEE
}

\begin{abstract}
A new approach to predict the additional costs of reactive power system services delivered by large hydrogenerators is proposed in this letter. It is based on the application of the accumulated average efficiency (AAE), which has recently been proposed. An optimal operational path within the capability diagram with minimal losses is derived. This path can be used to calculate additional losses from operational regimes deviating from the optimal one for each active power level. Finally, the additional losses are accumulated in a similar manner as the AAE to estimate the extra cost of the operational regime, with ideal operation as the reference. In addition, the accuracy of a data clustering approach is explored to speed up the computation of the AAE and the accumulation of additional costs.
\end{abstract}

Index Terms-Synchronous machines, hydrogenerators, cost modeling, loss modeling.

\section{INTRODUCTION}

B ULK power generation facilities act as the backbone for intermittent renewable energy resources, and in the future, they are projected to be pushed closer to their capability boundaries. This effect is highlighted in [1] $-[3]$, where the changes resulting from the German "Energiwende" can already be noticed. A price must be paid in terms of reduced efficiency in order to allow these intermittent services. An accumulated average efficiency (AAE) model was recently proposed to address this issue and improve the determination of the impact on the efficiency [4]. It was proposed as an alternative to the mainstreamed weighted average efficiency (WAE) model [5]-[7]. In this letter, the practical implementation of the AAE model is further explored, comparing the precise method [4], against the calculation based on clustering (i.e., zone classification) of load points. The precision of the simplified approach was investigated for a yearly production dataset, extending [4]. Finally, the most profitable operation of large synchronous generators is deduced, which is combined with the AAE-based accumulation technique to estimate the cost of an operational regime, including reactive power services.

\section{Clustering of Operation Data}

A load distribution dataset that tracks the synchronous generator loading every hour for a whole year of a $103 \mathrm{MVA}$

Manuscript submitted June 15, 2021 (Corresponding author: Yannick Cyiza Karekezi).

Y. C. Karekezi and J. K. Nøland is with the Norwegian University of Science and Technology (NTNU), Trondheim, Norway (e-mail: yannickk@stud.ntnu.no; jonas.k.noland@ntnu.no).

T. Øyvang is with the University of South-Eastern Norway (USN), Porsgrunn, Norway (e-mail: thomas.oyvang@usn.no).

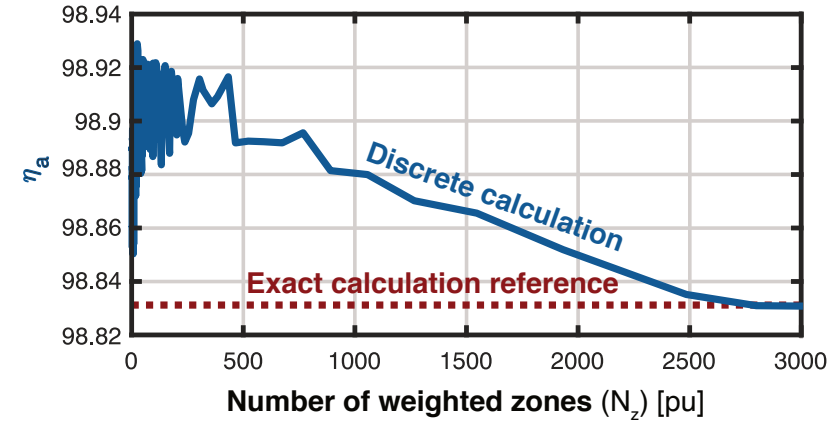

Fig. 1. Discrete calculation of the AAE efficiency for a yearly dataset of Åbjøra hydropower plant for an increasing number of weighted zones.

TABLE I

A QUANTITATIVE DEMONSTRATION OF THE RELATIONSHIP BETWEEN THE NUMBER OF ZONES AND AAE

\begin{tabular}{lcccc}
\hline \hline Description & \multicolumn{4}{c}{ Value } \\
\hline$N_{z}$ & 10 & 768 & 1546 & 2485 \\
$\eta_{a}$ & $98.9079 \%$ & $98.8956 \%$ & $98.8650 \%$ & $98.8351 \%$ \\
$\eta_{a}-\eta_{a, \text { ref }}$ & $0.0763 \%$ & $0.0640 \%$ & $0.0340 \%$ & $0.0035 \%$ \\
\hline \hline
\end{tabular}

hydropower plant has earlier been presented in [4]. As it contains 8610 distinct operating points, the sensitivity of clustering them into zones is explored to see if the calculation could be simplified. Based on the number of distinct load points inside each zone $(i)$, their weights $\left(A_{i}\right)$ are determined as $A_{i}=\frac{\Delta t_{i}}{T}$, where $\Delta t_{i}$ is the accumulated time of operation inside each zone, and $T$ is the total time. Fig. 1 and Table [ assesses the precision of clustering the data in the dataset. The accuracy is shown to be strongly dependent on the number of weighted zones, which approximates the production dataset. The discrete load points inside a zone is equivalent to the center point/exact load point of each zone and associated by their respective likelihood $\left(A_{i}\right)$. Four sample cases are depicted in Fig. 2 The zone considerations are a viable solution, but if the zones do not correctly approximated the clustering of the load points, it comes at the expense of the AAE calculation. This gives an error in comparison to the precise calculation using the actual operating points as a reference [4]. This is illustrated in Fig. 1 and Table 1 . The AAE starts to converge when the number of zones is increased to 768 , where it begins to approximate the load density of the dataset correctly.

\section{Losses AT Optimal LoAding And Cost Modeling}

The synchronous generator power loss model was derived in [4]. Fig. 3-a validates the power loss curves by seven sta- 


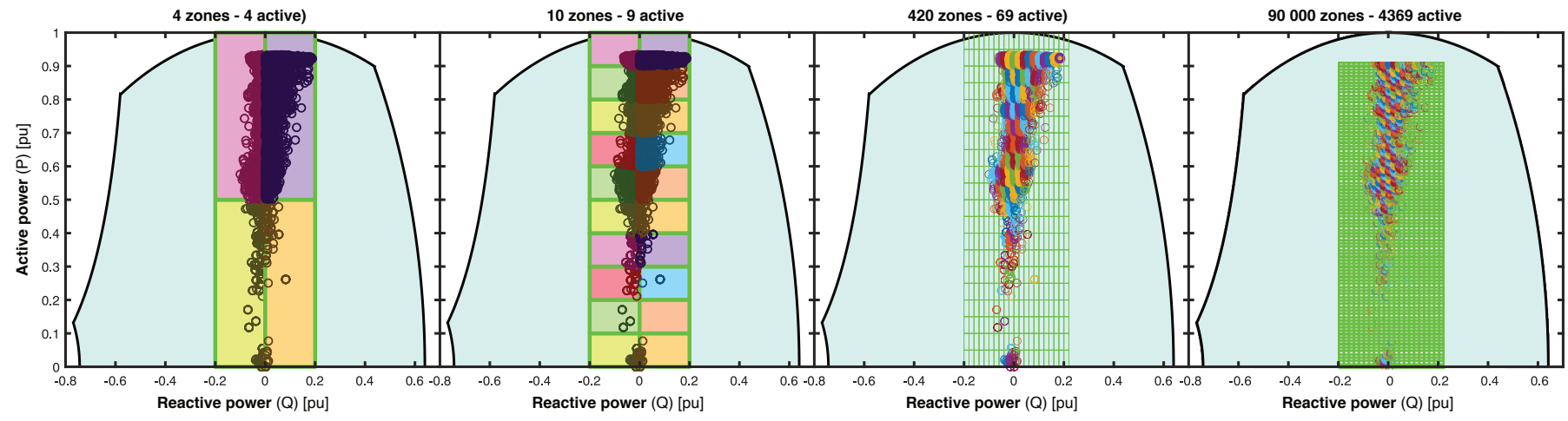

Fig. 2. Illustrates of discrete load points based on zone classification, giving exact load points for the Åbjøra power plant, showcased for $4,9,420$ and 4369 active zones, respectively. The load data was obtained from the University of Southeastern Norway.
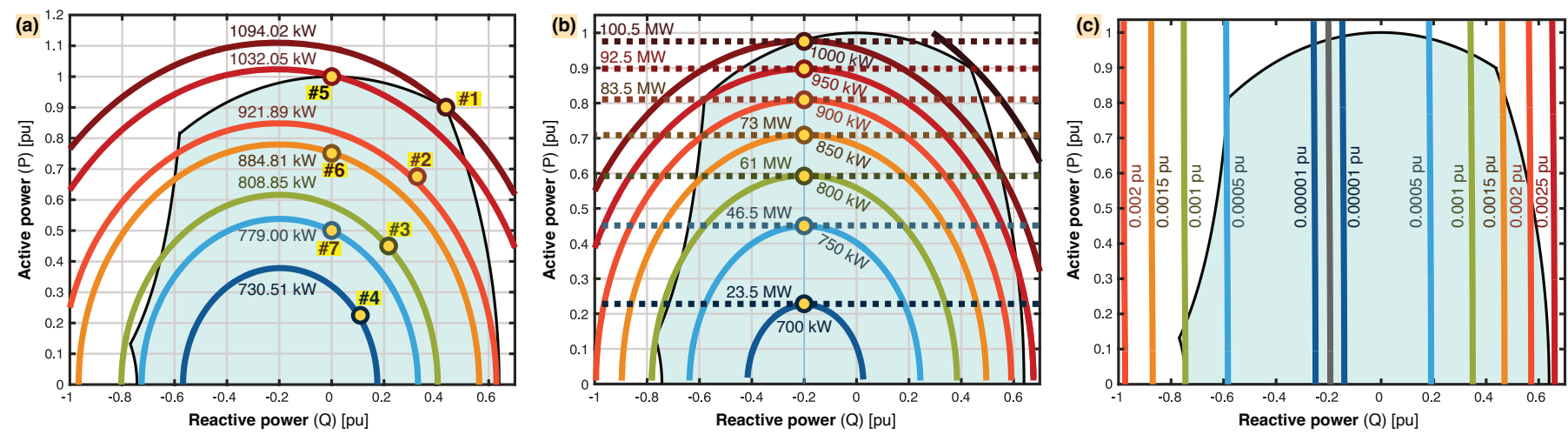

Fig. 3. Case study for a 103 MVA hydropower generator [4]. (a): Measurement verification of the predicted loss contours for seven different load points. (b): Combined plotting of power production lines and power loss curves extracted from the loss model. (c): Contour plot of eq. (2) for additional losses resulting from operating outside of the optimal $P-Q$ loading path (indicated in grey) inside and outside of the capability diagram.

tionary measurements. Furthermore, by combining the active power production lines for the capability diagram with the loss curves, an optimal operation path can be proposed, as illustrated in Fig. 3-b. The active power lines giving the lowest active power losses are those that intersect with the peak of the loss contours, which is about $-0.2 \mathrm{pu}$ in reactive power for this study case. Finally, by subtracting the minimal losses along the optimal $P-Q$ path, the additional losses are derived in Fig. 3-c. The loss minima imply the maximization of profit. For a given $P$, the optimalization with respect to $Q$ is found by differentiation, yielding

$$
\frac{d}{d Q}\left[P_{\text {loss }}(Q, P)\right]=0,
$$

where the solution, $Q_{o p t}(P)$, is the solution to reactive power enabling the minimum losses as functions of $P$. Fig. 4 - a further investigates the $Q_{o p t}(P)$ solution, with and without saturation, where the minimum losses are given in Fig. 4 b. It is shown that one needs to increase the consumption of $Q$ slightly as one increases $P$. The additional loss $\Delta P$ is

$$
\Delta P_{\text {loss }}=P_{\text {loss }}(Q, P)-P_{\text {loss }}\left(Q_{\text {opt }}, P\right) \propto\left(Q-Q_{\text {opt }}\right),
$$

which have been plotted in 2D and 1D in Figs. 3 $\mathrm{c}$ and 5 . Fig. 5 shows that it is the optimum interaction between the rotor and stator losses that determines $Q_{o p t}$ The accumulation of $\Delta P$ can be used to quantify the cost of not operating along the optimal reactive power path.

$$
\begin{aligned}
\Delta E_{\text {loss }} & =\sum_{i}^{n} \Delta P_{\text {loss }, i} \Delta t_{i}=T \sum_{i}^{n} \Delta P_{\text {loss }, i} A_{i}=T \overline{\Delta P}_{\text {loss }} \\
& =\Delta P_{\text {loss }, 1} \Delta t_{1}+\Delta P_{\text {loss }, 2} \Delta t_{2}+\ldots+\Delta P_{\text {loss }, n} \Delta t_{n} \\
& =T \underbrace{\left(\Delta P_{\text {loss }, 1} A_{1}+\Delta P_{\text {loss }, 2} A_{2}+\ldots+\Delta P_{\text {loss }, n} A_{n}\right)}_{\bar{P}_{\text {loss }}}
\end{aligned}
$$

Eq. (3) accumulates the additionally wasted energy either using the exact calculation with time intervals, or the simplified calculation method with weights, as assessed in Section II.

The handpicked average electricity price for the US in 2020 is $0.1066 \$ / \mathrm{kWh}$, which is taken as the basis for income and cost calculations herein. The income for a given $P$ is multiplied with the price and time $(\Delta t)$, and same for the cost associated with the $P_{\text {loss }}$. The gross profit is proportional to the production income minus the loss costs. As a result, the optimal profit strategy is operating at optimal operation that minimizes $P_{\text {loss }}$. The additional operational costs for a particular load point can be predicted by multiplying $\overline{\Delta P}_{\text {loss }}$ from eq. 2 with the electricity price $(0.1066 \$ / \mathrm{kWh})$ and the number of hours (h) of operation. Table II highlights that $Q \approx$ $-0.2 \mathrm{pu}$ is the most profitable operating point at rated $P$. In addition, Table III reveals that the most profitable operational regime is a concentrated load distribution due to a high income and relatively low operational cost because it mostly operates close to the optimal $Q$. In contrast, the synchronous condenser 
TABLE II

THE INCOME, COST AND PROFIT FOR SIX DIFFERENT LOAD POINTS AT SAME POWER LEVEL, $P=0.9 \mathrm{pu}$

\begin{tabular}{|c|c|c|c|c|c|c|}
\hline Point & $\# 1$ & $\# 2$ & $\# \mathbf{3}$ & $\# 4$ & $\# 5$ & \#6 \\
\hline Reactive power $(Q)$ & $-0.40 \mathrm{pu}$ & $-0.20 \mathrm{pu}$ & $0.00 \mathrm{pu}$ & $0.20 \mathrm{pu}$ & $0.40 \mathrm{pu}$ & $0.60 \mathrm{pu}$ \\
\hline Additional loss $\left(\Delta P_{\text {loss }}\right)$ & $1.31 * 10^{-4} \mathrm{pu}$ & $0 \mathrm{pu}$ & $1.36 * 10^{-4} \mathrm{pu}$ & $5.441 * 10^{-4} \mathrm{pu}$ & $0.0012 \mathrm{pu}$ & $0.0022 \mathrm{pu}$ \\
\hline Production income & $9881.80 \$ / \mathrm{h}$ & $9881.80 \$ / \mathrm{h}$ & $9881.80 \$ / \mathrm{h}$ & $9881.80 \$ / \mathrm{h}$ & $9881.80 \$ / \mathrm{h}$ & $9881.80 \$ / \mathrm{h}$ \\
\hline Los: & $102.90 \$ / \mathrm{h}$ & $101.50 \$ / \mathrm{h}$ & $102.95 \$ / \mathrm{h}$ & $107.4 \$ / \mathrm{h}$ & $114.95 \$ / \mathrm{h}$ & $125.56 \$ / \mathrm{h}$ \\
\hline Net profit & $9778.90 \$ / \mathrm{h}$ & $9780.40 \$ / \mathrm{h}$ & $9778.90 \$ / \mathrm{h}$ & $9774.4 \$ / \mathrm{h}$ & $9766.9 \$ / \mathrm{h}$ & $9756.3 \$ / \mathrm{h}$ \\
\hline
\end{tabular}

TABLE III

THE ADDITIONAL LOSS, INCOME, COST AND PROFIT FOR DIFFERENT DISTRIBUTIONS

\begin{tabular}{|c|c|c|c|c|c|c|c|c|}
\hline Distribution & $E$ & $E_{\text {loss }}$ & $\Delta E_{\text {loss }}$ & $\bar{P}_{\text {loss }}$ & $\overline{\Delta P}_{\text {loss }}$ & Income & Cost & Profit \\
\hline Concentrated dist. & $652.175 \mathrm{GWh}$ & $7.715 \mathrm{GWh}$ & $0.155 \mathrm{GWh}$ & $0.0087 \mathrm{pu}$ & $1.747 * 10^{-4} \mathrm{pu}$ & $69.522 \mathrm{M} \$$ & $0.822 \mathrm{M} \$$ & $68.7 \mathrm{M} \$$ \\
\hline Synchronous cond. mode & $165.98 \mathrm{GWh}$ & $6.82 \mathrm{GWh}$ & $0.513 \mathrm{GWh}$ & $0.0076 \mathrm{pu}$ & $5.680 * 10^{-4} \mathrm{pu}$ & $17.698 \mathrm{M} \$$ & $0.7310 \mathrm{M} \$$ & $16.967 \mathrm{M} \$$ \\
\hline
\end{tabular}

The exact AAE for the measured concentrated distribution is $98.83 \%$ with 8610 data points (see Fig. 2), the discretized AAE for uniformly distributed load is 98.27 with 641 discrete points with equal weight (over the whole capability diagram), and the AAE for synchronous condenser mode is $96.05 \%$ with 623 discrete points (uniformly distributed with synchronous condenser operation weighted to be $60 \%$ of the time), where all cases are taken from [4].
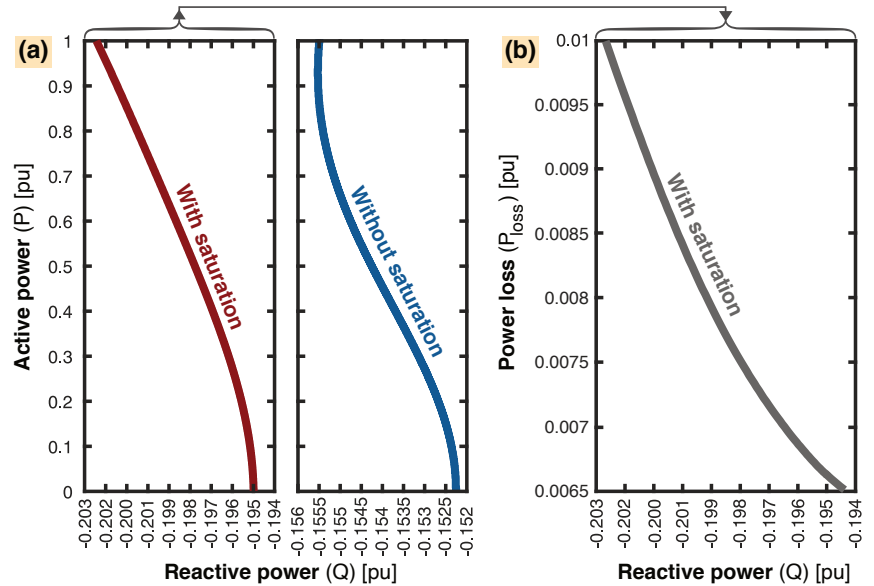

Fig. 4. Solution $Q_{o p t}(P)$ of eq. 11 for the loss model of the 103 MVA hydropower generator [4]. (a): Optimal $Q$ as a functions of $P$ with and without saturation. (b): Minimum $P_{\text {loss }}\left(Q_{o p t}\right)$ curve for the optimal $P-Q$ in (a).

dominated mode has the lowest profit due to long periods of low $P$, but it also has more than three times more additional losses (also extra cost) due to its reactive power services.

\section{CONCLUSiON}

In this letter, an operating strategy for efficiency maximization of a 103 MVA hydrogenerator has been developed, which minimizes losses and maximizes profit. It is revealed that the optimal load path of the machine inside the capability diagram implies consumption of approx. $0.2 \mathrm{pu}$ reactive power, independent of active power level. The low-loss operation condition can be used to estimate the practical cost of reactive power services, depending on how much the load point deviates from the optimal path. In addition, the accuracy of using clustered load data processing for obtaining a compact and practical calculation procedure of the efficiency was assessed against the exact calculation for a real production dataset. The simplified discretization can be used for additional loss calculation as well and used as a practical tool to map out the cost of power system services in intermittent operating regimes.

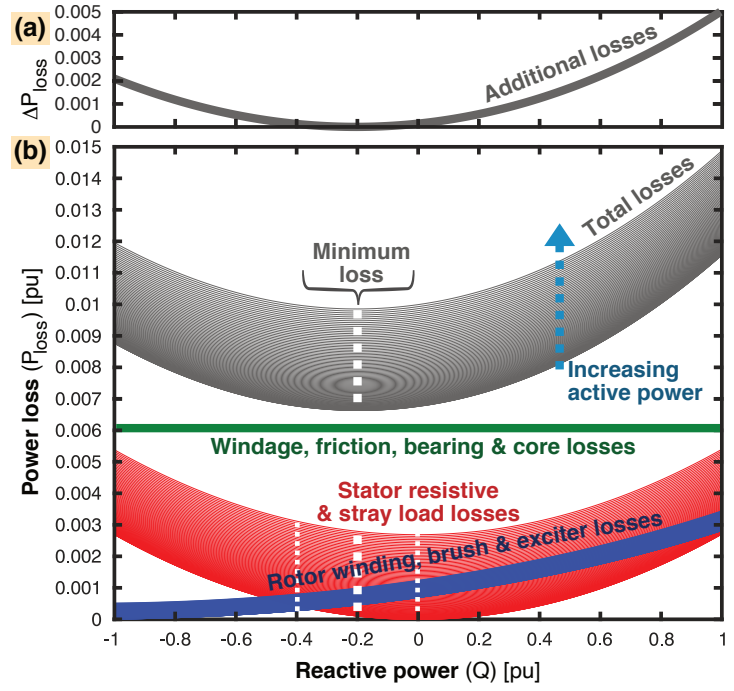

Fig. 5. 1D plots of the contours in Fig. 3 c for $100 P$ levels between 0 and 1 pu. (a): Difference between the absolute losses and the minimum losses, $\Delta P_{\text {loss }}$ from eq. 22. (b): Absolute losses, $P_{\text {loss }}(Q)$, for different $P$-levels.

\section{REFERENCES}

[1] J.-H. Braam, "Development, test and validation of new generator product line for current and future operational regimes," in Proc. Cigre, 2018.

[2] A. Joswig, K. Walli, and M. Baca, "Synchronous rotating equipment as backbone for renewables," in Proc. High Volt. Tech. Symp. VDE, 2018.

[3] J. K. Nøland, M. Leandro, A. Nysveen, and T. Øyvang, "Future operational regimes of bulk power generation in the era of global energy transition: Grid codes, challenges and open issues," in Proc. IEEE Power Energy Soc. Gen. Meet. (PESGM), 2020, pp. 1-5.

[4] Y. C. Karekezi, T. Øyvang, and J. K. Nøland, "The energy transition's impact on the accumulated average efficiency of large hydrogenerators," IEEE Trans. Energy Convers. (under review), 2021.

[5] E. d. C. Bortoni, R. T. Siniscalchi, S. Vaschetto, M. A. Darmani, and A. Cavagnino, "Efficiency mapping and weighted average efficiency for large hydrogenerators," IEEE Open J. Ind. Appl., vol. 2, pp. 11-20, 2021.

[6] "REPORT ON COORDINATION OF GRID CODES \& GENERATOR STANDARDS: Consequences of diverse grid code requirements on synchronous machine design \& standards," PES-TR69, Feb 2019.

[7] E. C. Bortoni, M. K. I. Uemori, B. T. Araujo, J. V. Bernardes, J. J. Rocha E., and R. T. Siniscalchi, "Accurate methodology to obtain efficiency mapping of synchronous machines," in Proc. IEEE Power \& Energy Soc. Gen. Meeting (PESGM), 2020, pp. 1-5. 